\title{
The political economics of not paying taxes
}

\author{
Jesper Roine* \\ SSE/EFI Working Paper Series in Economics and Finance \\ No 528
}

April 15, 2003

\begin{abstract}
This paper considers redistributive as well as political consequences of tax avoidance. When investing in tax avoidance is possible, the official tax rate does not necessarily correspond to what individuals actually pay in taxes. This affects both redistributive outcomes as well as individual's political attitudes towards taxation. Depending on the avoidance technology different political equilibria emerge. When the tax avoidance possibilities are limited, the classical conflict between rich and poor is sustained. If the tax avoidance technology is more effective, however, the equilibrium outcome can change to a situation characterized by a coalition of poor and the very richest favoring a higher tax rate. When comparing the model's predictions with data on income inequality and evidence of avoidance activity it comes surprisingly close to actual observations.
\end{abstract}

Keywords: political equilibrium, redistribution, tax avoidance, non-median voter equilibrium

JEL classification: D72, H20, H24

*STICERD, London School of Economics and Stockholm School of Economics. Thanks to Ioan Bejenaru, Anne Boschini, Sören-Bo Nielsen, Sten Nyberg, Mats Persson, Torsten Persson, Jan Pettersson, Michael Smart, Michael Tröge and Karl Wärneryd for helpful comments and suggestions. Thanks also to seminar participants at, London School of Economics, Northwestern University, The Research Institute of Industrial Economics and Stockholm University. Financial support from the Tore Browaldh and Jan Wallander foundation is gratefully acknowledged. 


\section{Introduction}

Redistributive policies are central elements of any democratic government's activities. Decisions about such policies have a common structure: members of society determine the size of taxes and transfers in a democratic process; decisions which are then presumed to be followed by everyone. This paper studies what happens in such a society if individuals have the possibility to invest in avoiding taxation, while still benefitting from the transfers? How does this change the possibilities to tax individuals and to redistribute income? How does tax avoidance change the income distribution in society? How does it affect people's political attitudes and, ultimately, the political equilibrium? These are questions that this paper sets out to answer.

There are several reasons for studying these questions. First of all, tax avoidance activities are empirically important. Among the many possible responses to taxation, there is a lot of evidence suggesting that people do engage in a wide variety of activities where the only purpose is to lower the individual tax burden. In quantitative terms, measures of the size of tax avoidance vary in the range of two to seven percent of GDP, depending on how it is defined and how it is estimated. ${ }^{1}$ In relation to other behavioral responses, the various tax avoidance activities are significant and, in particular, they seem to be more important than labor supply responses for the elasticity of the tax base. ${ }^{2}$ This is an important observation, since decisions on labor supply are often the corner-stone in political-economic models of redistribution (see e.g. Persson and Tabellini (2000) for an overview of this literature).

Second, the effects of tax avoidance on redistributive policies seem to be of particular interest. As noted by Gunnar Myrdal (1978) in a comment about the Swedish tax system, the incentives for high income earners to exploit various tax

\footnotetext{
${ }^{1}$ Gordon and Nielsen (1997), Nielsen et al. (2001) and Löfqvist (2001) obtain estimates for Denmark and Sweden, respectively, suggesting that between 4 and 6 percent of total income is avoided (2-4 percent of GDP). Andreoni, Erard and Feinstien (1998) report estimates for the US which suggest that about 20 percent of taxes owed are not paid. This is approximately 2 percent of GDP. At the high end of the estimates, Lang et. al. find a tax gap for Germany in 1983, which is 34 percent, corresponding to about seven percent of GDP.

${ }^{2}$ E.g. Slemrod (1992), Feldstein (1995), Agell, Englund and Södersten (1996), and Auerbach and Slemrod (1997).
} 
avoidance schemes can modify the tax system so that it no longer redistributes income. The reason for this could be that high-income earners often can choose tax favored forms of income or savings to a larger extent than others, but it could also be due to fixed-costs in tax avoidance activities. ${ }^{3}$ For example, hiring a tax consultant to file one's tax return may only be profitable if one has a sufficiently high income.

Third, if tax avoidance can change the redistributive properties of a tax system, this may also have political consequences. If rich individuals manage to avoid sufficiently large shares of their taxes, it is no longer obvious that they oppose high tax rates. A rich person who knows that he optimally will choose to invest in tax avoidance will vote accordingly. In the extreme situation where a rich individual can shelter all of his income, he will vote like a person who has no income. After all, what determines an individual's preferences over alternative tax rates is not her income, per se, but rather, her taxable income.

This paper develops a simple model of redistributive politics where individuals differ in endowed income. These individuals face two decisions. First, they choose how to vote in a majority rule election, which determines the tax rate. The tax is assumed to be proportional, and the tax revenue goes to lump-sum redistribution. Second, before taxes are paid and transfers received, individuals decide whether to invest in tax avoidance. The effects of these decisions (individual and aggregate) are, of course, taken into account at the time of the vote.

The investment in tax avoidance is assumed to be a binary choice under certainty, where a fixed cost enables an individual to avoid a known share of his tax payment. Hence, the focus is on legal tax avoidance, as oppose to illegal tax evasion. ${ }^{4}$ Different combinations of the cost and the share avoided can be considered as capturing different forms of tax avoidance activities. For example, a low cost leading

\footnotetext{
${ }^{3}$ See e.g. Agell and Persson (2000) for references.

${ }^{4}$ The analysis would obviously be the same even though the activity was illegal, as long the risk of being caught was zero. The distinction between legal (avoidance) and illegal (evasion) activities is, hence, not central to the interpretation of tax avoidance in this paper. What is central is that tax avoidance is a choice under certainty. In this sense, it is close to the formulations in Mayshar (1991) and Slemrod (2001). See Slemrod and Yitzhaki (2000) for a more detailed discussion.
} 
to a relatively small tax reduction approximates small-scale tax planning (standard legal advice or private time costs). High costs leading to large reductions instead approximate advanced schemes, such as the use of tax havens. In the basic set up of the model, only one avoidance option is available at a time. But a more complete specification permits both small scale and complete tax avoidance.

The problem of finding a political equilibrium turns out to be complicated. The tax avoidance opportunities imply that individual preferences are neither singlepeaked, nor order-restricted, for the general problem. Rather than restricting the problem to apply to the median voter theorem, a numerical method for solving the problem is developed.

The results turn out to depend on the tax avoidance technology. When avoidance possibilities are limited, the equilibrium tax rate is typically high and the political conflict between the rich and the poor remains. In equilibrium, high income earners thus prefer lower taxes, and low income earners favor higher taxes. However, as tax avoidance becomes less expensive (or more effective), the equilibrium tax rate goes down, and tax avoidance starts to alter the traditional division of attitudes toward tax changes. In the extreme case, where taxes can be completely avoided, support for a further increase of the tax rate, at the equilibrium, comes from an unusual coalition of voters. The poor favor an increase because their income is low, and the rich favor it because their taxable income is zero, due to their tax avoidance investments. When the model is solved for a range of reasonable parameters the model seems to give surprisingly accurate predictions, when compared to data.

This paper attempts to bridge two strands of literature. The first is the work in political economics concerned with general redistributive programs, following Romer (1975), Roberts (1977) and Meltzer and Richard (1981) (see Persson and Tabellini (2000) for a comprehensive survey of this literature). As noted above, much of this literature assumes that the relevant response to taxation is changes in labor supply, and therefore focuses on the interaction between voting and labor supply. In contrast, this paper - in light of the empirical finding that tax avoidance seems more 
important than labor supply responses - instead studies the interaction between voting and tax avoidance. The second strand of literature is the work in public economics on tax avoidance (see Slemrod and Yitzhaki (2000) for an overview). Here, several papers stress different forms of tax avoidance and the interplay between avoidance and labor supply decisions (such as Mayshar (1991), Agell and Persson (2000) and Slemrod (2001). None of these papers, however, consider the endogenous, democratic choice of the tax rate, which is a key aspect in this paper.

The paper is organized as follows. Section 2 presents the basic model and shows how tax avoidance has an impact on the size of transfers and how it affects individual preferences over tax rates. In Section 3, the problems with the non-applicability of the median voter theorems are discussed, and the numerical method for finding the political equilibrium is outlined. In Section 4, the model is solved and in Section 5 the model's predictions are confronted with data. Section 6 concludes the paper.

\section{The model}

The economy considered here is populated by a continuum of individuals assumed to have identical increasing and concave utility functions over consumption, $u(c)$. Individuals differ in endowed income, $w$, which is distributed according to a continuously differentiable c.d.f., $\Phi(w)$, with support $[0, \infty)$, and for each positive level of $w$, there is a positive density given by $\varphi(w)=\Phi^{\prime}(w)$. The population is normalized to one and, hence, aggregate income is equal to the mean income denoted by $\bar{w} \equiv \int_{0}^{\infty} w \varphi(w) d w$. The median income, $w^{m}$, is assumed to be lower than the mean income, i.e. $w^{m}<\bar{w}$.

A proportional tax, $t \in(0,1]$, is used to finance a lump-sum transfer of $r$ units of consumption, which is received by everyone. However, individuals can avoid paying a share $(1-\delta), \delta \in[0,1]$, of the tax, through investing a lump-sum $A \in[0,+\infty)$ in tax avoidance. This means that if an individual, with income $w$, invests $A$, he will only pay $\delta w t$ in taxes, rather than the full, official amount wt. This binary formulation of the tax avoidance is chosen partly to simplify the analysis, but also since 
many real-life avoidance activities involve such fixed-cost investments. Furthermore, this formulation covers a large number of functional forms where the amount avoided is an increasing function of how much is invested in tax avoidance. ${ }^{5}$ The option to make this investment is available to everyone, and the parameters describing the tax avoidance technology, $(A, \delta)$, are assumed to be exogenously given. ${ }^{6}$ Different combinations of $A$ and $\delta$ can be thought of as representing different forms of avoidance activities. For instance, a combination of a low value of $A$ and a high value of $\delta$ represent small-scale tax planning which has a relatively low cost, but is also relatively inefficient (standard accounting advice or private time-costs). The opposite combination of a high value of $A$ and a low value of $\delta$ implies costly but efficient tax avoidance (advanced tax planning). ${ }^{7}$

\subsection{Individual decisions}

Individuals in this economy face two decisions. A political decision of how to vote in the majority election that determines the tax rate, and a binary choice of investing or not investing in tax avoidance. These decisions are obviously linked since the individual choice of whether to invest in tax avoidance depends on the tax rate, just as an individual's choice of how to vote, depends on whether he will choose to avoid taxes. Assuming that the avoidance decision can be taken at any point in time, while the election date is fixed, implies that it is made in response to the election

\footnotetext{
${ }^{5}$ If the proportion of taxes avoided $\delta$ was a function of the amount invested $A$, the optimal investments would correspond to the binary choice formulation used here for all functions that exhibit increasing returns to scale. More precisely, if the problem is to maximize $u((1-\delta(A) t) w+$ $r-A$ ) w.r.t. $A$, with $\delta^{\prime}(A)<0$, this has a f.o.c, $-\delta^{\prime}(A) t w-1$, implying that an interior solution is implicitly given by $-\delta^{\prime}(A)=\frac{1}{t w}$, only if $\delta^{\prime \prime}(A)>0$. If $\delta^{\prime \prime}(A) \leq 0$, that is, if there are increasing returns to avoidance, only corner solutions can be optimal. Hence, the formulation with avoidance being a binary choice covers all cases with increasing returns to tax avoidance investments.

${ }^{6} \mathrm{It}$ could of course be argued that $\delta$ also should be endogenous, since it is a matter of tax design to determine how much avoidance is allowed. This would, however, create a multi-dimensional setting, complicating the analysis of political equilibria. Furthermore, loop-holes and unintended (but still legal) tax deductions seem to be an inate feature of any tax system, see e.g. Shackelford (2000).

${ }^{7}$ In sections two and three, only one avoidance possibility will be available at a time (either a low $A$ and a high $\delta$, or vice versa). However, in sections four and five, there will be both less expensive and less efficient, as well as costly, advanced forms of avoidance available simultaneously.
} 
outcome. $^{8}$

Given this sequence, the optimal avoidance decision is simple. For any given tax rate, an individual chooses to invest in tax avoidance if that choice results in higher utility than paying full taxes, that is if

$$
u(w-\delta t w+r-A)>u(w-t w+r) .
$$

The critical income, $w^{*}$, follows directly from the indifference condition

$$
w^{*}-A-\delta t w^{*}+r=w^{*}-t w^{*}+r
$$

which gives that

$$
w^{*}=\frac{A}{(1-\delta) t} .
$$

This means that at any tax rate, there is a unique income, $w^{*}$, which splits the population into two parts. Those with an income below $w^{*}$ pay full taxes, while those with a higher income choose to avoid a share $\delta$ of their tax payment. From (1), we see that $w^{*}$ is increasing in $A$ and in $\delta$, while it is decreasing in $t$. This means that the more expensive is tax avoidance, (the higher is $A$ ), and the less the investment reduces taxes, (the higher is $\delta$ ), the higher must the individual's income be for tax avoidance to be profitable. Similarly, the higher the tax rate, the smaller is the critical income for choosing to avoid taxes. Individuals with $w<A /(1-\delta)$ will, however, never find it profitable to invest in tax avoidance. Formally, $w^{*} \in\left[\frac{A}{(1-\delta)},+\infty\right)$ and $\frac{\partial w^{*}}{\partial t}<0$.

An individual's preferences over tax rates depend on whether or not he avoids taxes. For an individual with income $w$, the induced utility function, $v$, can be

\footnotetext{
${ }^{8}$ If the order were reversed, so that the avoidance decision had to be taken before the election, and could not be changed afterwards, a problem similar to the so-called "capital levy problem" in the capital taxation literature would emerge (see e.g. Persson and Tabellini (1994b)). There would be no ex post possibility to escape taxation and in the absence of a commitment mechanism, no tax rate other than $t=1$ would be credible. Anticipating this, everyone optimally choosing to invest in avoidance at this tax rate would do so before the election.
} 
written as

$$
v(w, t ; A, \delta)=\max \left\{\begin{array}{cc}
u(w-t w+r) & \text { if } w \leq w^{*} \\
u(w-A-\delta t w+r) & \text { if } w>w^{*}
\end{array}\right.
$$

where $w^{*}$ is given by (1) and $r$ is the transfer. Since the transfer is a function of the tax rate, the relevant derivatives are given by

$$
\left.\frac{d v(\cdot)}{d t}\right|_{w \leq w^{*}}=u^{\prime}\left[-w+r^{\prime}(t)\right]
$$

and

$$
\left.\frac{d v(\cdot)}{d t}\right|_{w>w^{*}}=u^{\prime}\left[-\delta w+r^{\prime}(t)\right],
$$

respectively. These equations give the relevant first-order conditions for individuals who at tax rate $t$ pay taxes in full, given by (3), as well as the first-order conditions for those who at $t$ optimally invests in tax avoidance and only pays part of his taxes, given by (3). Individual utility is, hence, well defined and continuous over all tax rates, but can be kinked at the point $t=A /(1-\delta) w$.

\subsection{Budget balance}

Individual tax avoidance decisions affect redistribution. Requiring the budget to be balanced gives the following expression for aggregate per capita expenditure on transfer payments:

$$
r(t)=t \int_{0}^{w^{*}(t)} w \varphi(w) d w+\delta t \int_{w^{*}(t)}^{\infty} w \varphi(w) d w
$$

which can be simplified to

$$
r(t)=t\left[\delta \bar{w}+(1-\delta) \int_{0}^{w^{*}(t)} w \varphi(w) d w\right] .
$$

The transfer function is a continuous function $r:[0,1] \rightarrow R_{+}$with $\lim _{t \rightarrow 0} r(t)=0$ and $r(1)=\delta \bar{w}+(1-\delta) \int_{0}^{\frac{A}{(1-\delta)}} w \varphi(w) d w<\bar{w}$. The interpretation of equation (6) is that everyone, including tax avoiders, pay $t \delta w$, while those with an income below 
$w^{*}$, also pay an additional amount, $t(1-\delta) w$. Thus, increasing the tax rate has two opposing effects on the size of the transfer. On the one hand, there is a positive effect on $t \delta \int_{0}^{w^{*}(t)} w \varphi(w) d w$ while, on the other, as $t$ goes up, $w^{*}$ goes down, i.e. more people choose to avoid tax and hence, the share of individuals paying full taxes goes down. Formally, differentiating (6) with respect to $t$ gives

$$
r^{\prime}(t)=\delta \bar{w}+(1-\delta) \int_{0}^{w^{*}(t)} w \varphi(w) d w-\frac{A}{t} w^{*} \varphi\left(w^{*}\right),
$$

and the second derivative

$$
r^{\prime \prime}(t)=\frac{A^{2}}{(1-\delta) t^{3}}\left(\varphi\left(w^{*}\right)+w^{*} \varphi^{\prime}\left(w^{*}\right)\right) .
$$

From (7), we see that the marginal effect on the transfer function is composed of three parts. The first part, $\delta \bar{w}$, is a positive constant capturing the fact that everyone pays at least a share $\delta$ of the taxes, regardless of the tax rate. The second part, $(1-\delta) \int_{0}^{w^{*}(t)} w \varphi(w) d w$, is positive and strictly decreasing in $t$, since the fraction of the population paying full taxes is strictly decreasing in the tax rate. The third part, $-\frac{A}{t} w^{*} \varphi\left(w^{*}\right)$, captures the negative marginal effect of individuals shifting from paying full taxes to avoiding tax. The aggregate impact on the size of redistribution is ambiguous and depends on the relative size of these effects.

From equation (8), we can see that a formal condition for $r(t)$ to be concave is that $\varphi\left(w^{*}\right)+w^{*} \varphi^{\prime}\left(w^{*}\right)<0 .{ }^{9}$ However, there is no reason for why this condition should hold in general and the transfer function may therefore be non-concave. ${ }^{10}$

\footnotetext{
${ }^{9}$ This expression has an interpretation since $\varphi\left(w^{*}\right)+w^{*} \varphi^{\prime}\left(w^{*}\right)<0$ implies that $\frac{d}{d w^{*}}\left(w^{*} \varphi\left(w^{*}\right)\right)<$ 0 which, in turn, means that $w^{*} \varphi\left(w^{*}\right)$ must be strictly decreasing on the interval $\left[\frac{A}{1-\delta}, \infty\right)$. In words, as the tax rate goes up, the value of the marginal loss due to tax avoidance (given by the size of $w^{*}$ times the density at this point, $\left.\varphi\left(w^{*}\right)\right)$ must be increasing in the tax rate for the transfer function to be concave. Alternatively, the condition for concavity can also be expressed by the following elasticity condition: $\frac{w^{*}}{\varphi\left(w^{*}\right)} \frac{\partial \varphi\left(w^{*}\right)}{\partial w^{*}}<-1$.

${ }^{10}$ Indeed, the simulations made in Section 4 show that the transfer function is non-concave for many parameter configurations of the model.
} 


\section{Political equilibrium}

The tax rate is chosen in a majority vote and a political equilibrium can therefore be defined as a tax rate, $t$, with a corresponding level of redistribution, $r$, given by equation (6), such that no other tax rate is preferred by a majority of the population. Even though this formulation covers several voting procedures, the setting considered here is standard Downsian, two-candidate competition. That is, two parties (candidates) who only care about winning the election, suggest policies (tax rates), to which they can commit. Individuals then vote for their favorite candidate (the one whose policy gives them the highest utility), with a complete understanding of the consequences of each policy and, finally, the winning policy is implemented. If, in this context, there is a policy, $t^{*}$, which is majority preferred to all other policies, both parties will optimally suggest this policy, and both will face an equal chance of winning the election. Regardless of who wins the election, the policy outcome will be the political equilibrium tax rate, $t^{*}$.

The analysis of individual decisions and the consequences of tax avoidance for the size of transfers discussed in the previous section, indicate that there is no simple way of solving for the political equilibrium in general. The fact that the transfer function is not necessarily concave means that the individual optimization problem may have multiple solutions, and also that corner solutions may be optimal. More importantly, individual utility is not necessarily single-peaked, nor is it order restricted and, hence, none of the standard median voter theorems apply in general. ${ }^{11}$ The simplest way of seeing under what conditions the median-voter theorems fail is to consider the case when tax avoidance is complete, i.e. $\delta=0$, and consider a rich individual's changes of utility over the tax rate. As long as the tax rate is so low that the individual does not optimally invest in tax avoidance, the utility falls as the tax rate goes up, since the individual's tax payment is larger than the transfer he

\footnotetext{
${ }^{11}$ The restrictions on preferences that give the different versions of Median Voter Theorem are that preferences be either single-peaked (due to Black, 1948) or order-restricted (as in Roberts (1977). See Austen-Smith and Banks (1999) for a comprehensive treatment of these different median voter theorems.
} 
receives. Consequently, he would vote against higher taxes in this range. However, at the point where the individual chooses to invest in tax avoidance, the utility over $t$ starts to increase (as long as the transfer function $r(t)$ is increasing), due to the fact that the individual no longer pays any taxes, but does receive the (positive) transfer. This implies that when the rich individual is faced with two alternatives in the range of tax rates where he avoids taxes, he will vote as if he had no income at all, i.e. so as to maximize transfers.

Figure 1 illustrates how individual utility over tax rates changes for three individuals with different income. The left hand panel shows the utility over tax rates for a low, a middle and a high income individual when tax avoidance is relatively inexpensive but only leads to small tax reductions. In this situation both the middle and the high income individual would invest in tax avoidance at different points. The rich individual invests at a relatively low tax rate, $t=0.25$ (as can be seen by the kink in the utility curve) leading to a change in the marginal effect for tax rates above this point. For the middle income earner it does not pay to invest in avoidance until the tax rate reaches $95 \%$ (this is hardly detectable in the figure). As can be seen from the figure, utility remains single peaked despite the investments in avoidance. In contrast, the right hand panel shows a setting where avoidance is expensive but complete, i.e. when the cost $A$ has been paid the individual no longer pays any tax. In this case only the richest individual finds it optimal to invest in tax avoidance (at $t=0.37$ ), leading his utility to increase as described above. The decrease in utility for all three individuals for high tax rates is due to the transfer function $r(t)$ being decreasing due to extensive tax avoidance in the high range of tax rates.

This does not only mean that the "identity" of the decisive voter may be unknown (and changing) depending on the tax avoidance parameters but also that there may be situations when there is no equilibrium. This problem could of course be addressed by limiting the analysis to situations where the median voter theorem holds. ${ }^{12}$ There is, however, no compelling reason for doing so. Instead of limiting

\footnotetext{
${ }^{12}$ It would, for example, be possible to restrict the avoidance parameters, so as to ensure that
} 

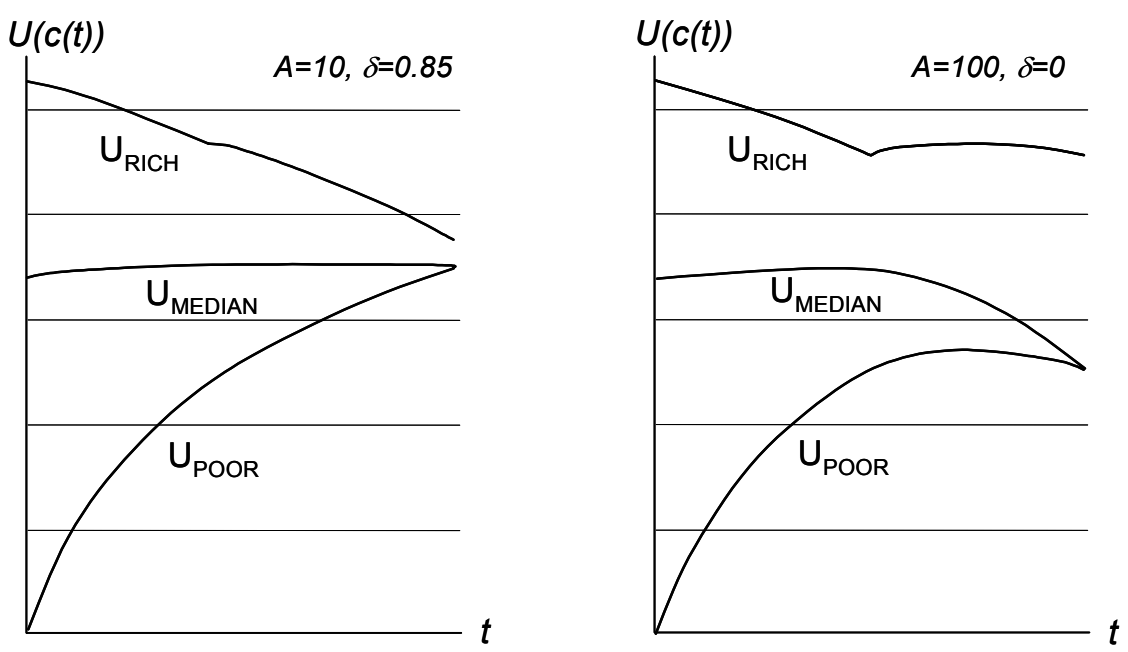

Utility function: $\log (c)$, Underlying income distribution: Weibull $(0,90,1.8)$, Representative individuals have pre-tax income: $w=0$ (Poor), $w=70$ (Median), $w=275$ (Rich, top 1\%).

Figure 1: Utility over tax rates for three representative individuals. To the left a setting where tax avoidance inexpensive but inefficient, to the right a case where avoidance is expensive and complete.

the problem, and possibly leaving out some interesting cases, we develop a simple and intuitively tractable, numerical method for finding political equilibria.

The method is based on using local (first-order) conditions to find tax rates which are local equilibria. Such equilibria can then be compared to (a dense grid of) all other tax rates. If a local equilibrium tax rate turns out to be preferred to all other tax rates by a majority of the population, then it can be concluded that it is also the global political equilibrium. If, on the other hand, there should be no local equilibrium which is majority preferred to all other tax rates, it can be concluded that there is no political equilibrium. The method rests on some results from the previous section and a few simple theoretical observations. ${ }^{13}$

First recall that, at any tax rate, the population is, by equation (1), uniquely preferences remain single peaked. Another possibility would be to consider a simplified (threegroup) income distribution which would enable a complete analytical solution (as in Fernandez and Rogerson (1995)).

${ }^{13}$ The method is very similar to the computational model developed in Epple and Romano (1996). An important difference is, however, that the method developed here also finds corner solutions which turn out to be important in the context of this paper. 
divided into those avoiding tax and those who do not. The measure of full tax payers, at any $t$, is given by $\Phi\left(w^{*}\right)$, and that of tax avoiders by $1-\Phi\left(w^{*}\right)$. Within these respective groups, individuals have well defined first-order conditions for marginal changes of the tax rate, given by equations (3) and (4). These simply state that a marginal increase of the tax rate changes an individual's utility by a term consisting of the individual's increased tax payment (given by $w$ or $\delta w$ depending on whether the individual avoids tax) and another term, $r^{\prime}(t)$, which is the change in the size of the transfer. Clearly, if the marginal increase in transfers is larger than the marginal increase in the tax payment, an individual would be in favor of such a marginal change. From this we can conclude the following:

Lemma 1 At any tax rate $t$, all individuals who pay full taxes (i.e. have an income $\left.w \leq w^{*}\right)$ and also have an income $w<r^{\prime}(t)$, prefer the marginally higher tax rate $t+\varepsilon$, as compared to $t$. Among individuals avoiding taxes (i.e. with an income $\left.w>w^{*}\right)$ everyone with $w<r^{\prime}(t) / \delta$ also prefers the marginally higher tax rate, $t+\varepsilon$ to $t$.

Obviously, Lemma 1 does not say anything about the individual's preferred tax rate. It just characterizes which individuals favor a marginal change from $t$ to a marginally higher tax rate $t+\varepsilon$. As will be shown, however, these conditions are very useful for finding a global equilibrium policy (if one exists). Using Lemma 1, we can obtain an expression for the share of the population which, at any $t$, favors a marginal increase of the tax rate, by simply adding together, everyone who share a certain marginal preferens. First, define an income level $w^{f}=r^{\prime}(t)$ as the income level at which the first-order condition (3) for a full tax payer is fulfilled and, equivalently, define $w^{a}=r^{\prime}(t) / \delta$ as the income level at which the first-order condition (4) for a tax avoider is fulfilled. With these definitions, we can describe the aggregate support for a marginal increase of the tax rate by the following:

Lemma 2 The total support for a marginal increase of the tax rate is, at any $t$, 
given by

$$
H(t)=\left\{\begin{array}{ll}
\Phi\left(w^{f}\right) & \text { if } w^{f} \in\left(0, w^{*}\right] \text { and } w^{a} \notin\left(w^{*}, \infty\right) \\
\Phi\left(w^{f}\right)+\left[\Phi\left(w^{a}\right)-\Phi\left(w^{*}\right)\right] & \text { if } w^{f} \in\left(0, w^{*}\right] \text { and } w^{a} \in\left(w^{*}, \infty\right) \\
\Phi\left(w^{a}\right) & \text { if } w^{f} \notin\left(0, w^{*}\right] \text { and } w^{a} \in\left(w^{*}, \infty\right) \\
0 & \text { if } w^{f} \notin\left(0, w^{*}\right] \text { and } w^{a} \notin\left(w^{*}, \infty\right)
\end{array} .\right.
$$

These four cases have straightforward interpretations. The first case, when $H(t)=\Phi\left(w^{f}\right)$, is a situation when only the low end of the income distribution favors an increase of the tax rate, simply because they are the only ones gaining from higher taxes. Even though a share of the population avoid part of their taxes, everyone in this group is still a net contributor to the redistributive system (as is the case when avoidance leads to very small tax reductions, for example, in situations where $\delta \rightarrow 1$ ). In the second case, at least part of those avoiding taxes (those with an income between $\left.\Phi\left(w^{a}\right)-\Phi\left(w^{*}\right)\right)$ are also in favor of a marginal increase, due to the fact that they now receive more than they pay. This is typically the case when avoidance is efficient (low values of $\delta$ ). In the limit, as $\delta \rightarrow 0$, everyone in the richest fraction of the population $\left(1-\Phi\left(w^{*}\right)\right)$ favors a marginal tax increase. In the third case, everyone who pays full taxes as well as a share of those who avoid taxes favor an increase of the tax rate while in the fourth and final case, no one does (this is the case when $r^{\prime}(t)$ is negative). ${ }^{14}$

Figure 2 shows examples of how the population can be split in two different equilibrium situations. The left hand diagram shows a traditional situation where individuals with low income would like higher taxes compared to the equilibrium, while the richer half of the population would prefer a lower tax rate, even though part of the population (those above $w^{*}$ ) avoid taxes. The right hand diagram shows a different split, where the rich individuals now instead would prefer a higher tax rate due to their investments in tax avoidance.Using the function $H(t)$, we can formulate the following necessary condition for an interior political equilibrium:

\footnotetext{
${ }^{14}$ The formulation of $H(t)$ clearly implies that the share of the population opposing a marginal increase is given by $1-H(t)$. The weight of indifferent individuals, as well as those shifting from paying full taxes to tax avoidance given by $\Phi\left(w^{*}(t)\right)-\Phi\left(w^{*}(t+\varepsilon)\right)$, when $\varepsilon \rightarrow 0$, is zero.
} 

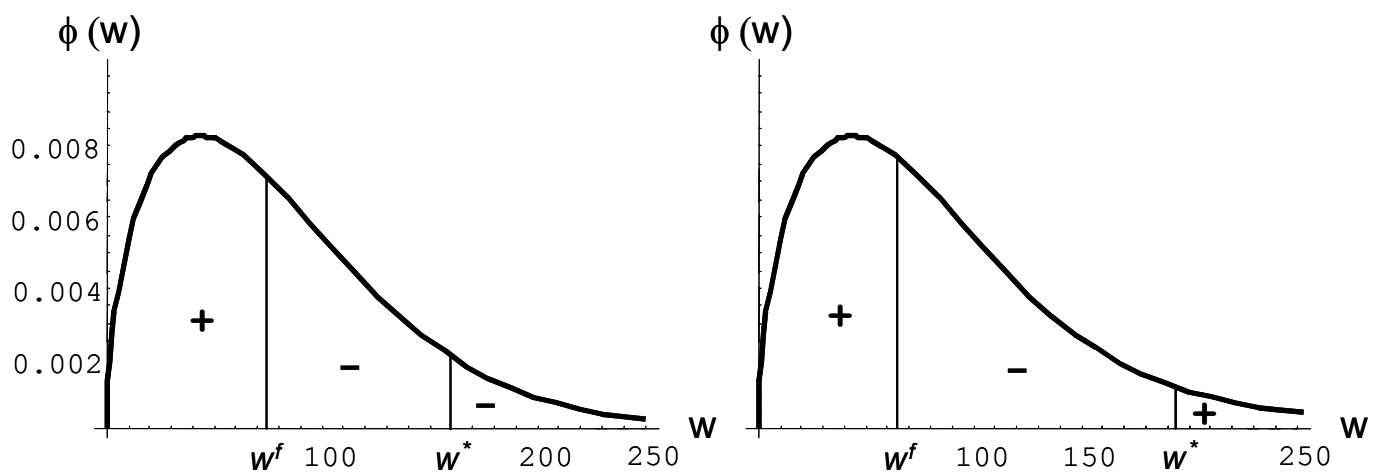

Figure 2: Marginal preferences of different segments of the population in two equilibrium situations. To the left a traditional case, to the right a coalition between rich and poor, with the rich tax avoiders preferring an increase compared to the equilibrium.

Proposition 1 For a tax rate, $t \in(0,1)$, to be a political equilibrium, the share of the population in favor of a marginal increase must be equal to half the population, i.e. $H(t)=\frac{1}{2}$.

Proof. Consider any $t \in(0,1)$, such that $H(t)<\frac{1}{2}$. Then, there exists a tax rate $t^{\prime}<t$, such that more than half the population prefers $t^{\prime}$, and hence $t^{\prime}$ would gain more votes than $t$ in a majority vote. Similarly, if $H(t)>\frac{1}{2}$, there exists a tax rate $t^{\prime \prime}>t$ such that $t^{\prime \prime}$ is preferred by more than half the population and, consequently, $t^{\prime \prime}$ would beat $t$ in a majority vote. This means that the only time that $t \in(0,1)$ can be a political equilibrium is when $H(t)=\frac{1}{2}$.

Note that the proposition is stated for interior solutions, i.e. $t \in(0,1)$. Regarding the possibility of corner solutions, the tax rate $t=1$ is a possible equilibrium if $H(1) \geq \frac{1}{2}$, while for $t=0$ to be an equilibrium, it must be the case that $H(0) \leq \frac{1}{2}$. The latter is never true when the median is poorer than the mean income earner.

Finally, we can note the following obvious relationship between a local equilibrium and a (global) political equilibrium, which defines a necessary and sufficient condition for a political equilibrium in this setting: 
Proposition 2 A (global) political equilibrium is a local equilibrium tax rate, which is also majority preferred to all other tax rates.

The observations and propositions made above suggest a simple structure for how to solve the problem of numerically finding the political equilibrium.

1. Compute $w^{*}(t), r(t)$ and $r^{\prime}(t)$ (given by equations (1), (6) and (7)), given the initial distribution of income $\Phi(w)$ and the values of the tax avoidance parameters, $A$ (cost) and $\delta$ (efficiency).

2. Use these functions and Lemma 1 to calculate $H(t)$ over all $t$ and find points where $H(t)=\frac{1}{2}$ (and possibly $H(1) \geq \frac{1}{2}$; plotting $H(t)$ gives information on whether corner solutions need to be considered).

3. Compare local equilibrium points with (a dense grid of) all other tax rates. If no local equilibrium tax rate is majority preferred to all other tax rates, we can conclude that no political equilibrium exists. But ,as stated in Proposition 2 , if a local equilibrium is majority preferred to all other tax rates, it is the political equilibrium.

\section{Solving the model}

Using the method outlined in the previous section, the model can be solved for any (continuous and well-behaved) initial income distribution, and any combination of tax avoidance parameters. Obviously, some parameter values are more interesting than others, in that they capture real-world aspects of the problem. As will be shown in Section 4.1, the solutions turn out to have certain monotonicity characteristics which enable a division of the outcomes into two broad classes of interest, defined by the type of tax avoidance activity studied: equilibria when tax avoidance is cheap and inefficient ("standard" tax planning) and equilibria when avoidance is expensive and efficient ("advanced" tax avoidance). In Section 4.2 the effect of having both these opportunities available simultaneously is studied. 


\subsection{Political equilibria with tax avoidance}

Even though we may have a some idea of the kinds of tax avoidance activities for which the parameters are approximations, their exact size is obviously unobservable. Equilibria will, therefore, be computed for a range of reasonable parameters. In all cases, the (pre-tax) income is assumed to be Weibull distributed with parameter values chosen so as to approximate actual distributions of market income. ${ }^{15}$ Figure 3 shows the span of different income distributions used, with the benchmark distribution in bold. ${ }^{16}$
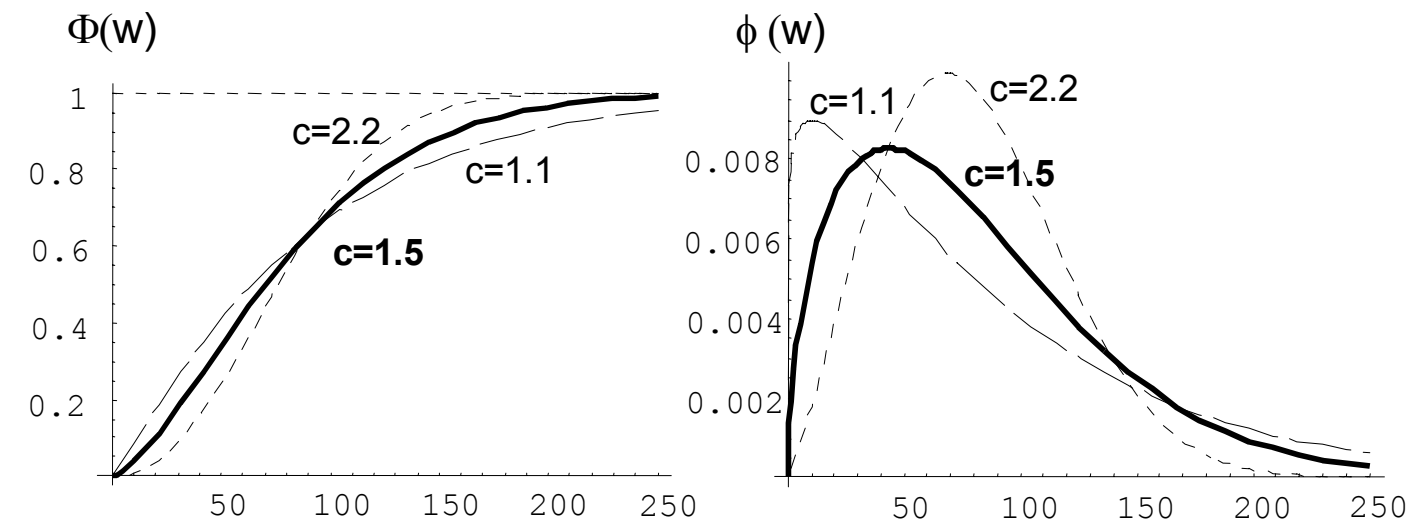

Figure 3: Distributions of initial income based on the Weibull distribution.

The political equilibrium tax rates for the benchmark distribution and a range of tax avoidance parameters are shown in Figure 4. The monotonicity of the equilibrium outcomes enables us to characterize four types of outcomes, each with an intuitive explanation.

There are two types of extreme outcomes. Starting in the upper left-hand corner we have cases where tax avoidance is both expensive and inefficient. For example, the

\footnotetext{
${ }^{15} \mathrm{~A}$ random variable $W$ is Weibull $(a, b, c)$ if, for all $w \in \Re: \operatorname{Pr}(W \leq w)=1-e^{-\left(\frac{w-a}{b}\right)^{c}}$. The values of $a$ and $b$ determine the lower end and the scale of the support, respectively. These values are kept fixed with $a=0$ and $b=90$, while $c$ varies between 1.1 (low concentration, i.e. high income inequality) and 2.2 (high concentration, that is low income inequality) with 1.5 as the benchmark. In terms of Gini-coefficients, this means varying the distribution between approximately 0.5 and 0.25 , which should cover most actual distributions.

${ }^{16}$ The benchmark has a Gini coefficient of 39.3. A simple average of market income for all countries included in the OECD Economic Studies, No. 29, 1997/II report, and the Luxembourg Income Study (reported in OECD Social Policy Studies No. 18, 1995) is 39.5.
} 
parameter combination $A=100, \delta=0.9$, means that at a cost equal to the average income in the economy an individual can get a $10 \%$ tax reduction. Even for high tax rates, this is attractive only to very few individuals and hence, the loss of tax base from increased taxation is small, resulting in that a majority of the population would, in such a situation, favor a tax rate of $100 \%$. The opposite extreme is found in the lower right-hand corner. Here avoiding taxes is instead relatively cheap and very effective. When tax avoidance opportunities are, for example, characterized by $A=10$ and $\delta=0$ anyone can avoid taxes completely at a cost of only $10 \%$ of the average income. This leads to a situation where higher tax rates would be associated with so much avoidance activity that the equilibrium ends up being a tax rate of only $3 \%$.

The equilibrium tax rate drops as avoidance becomes more effective

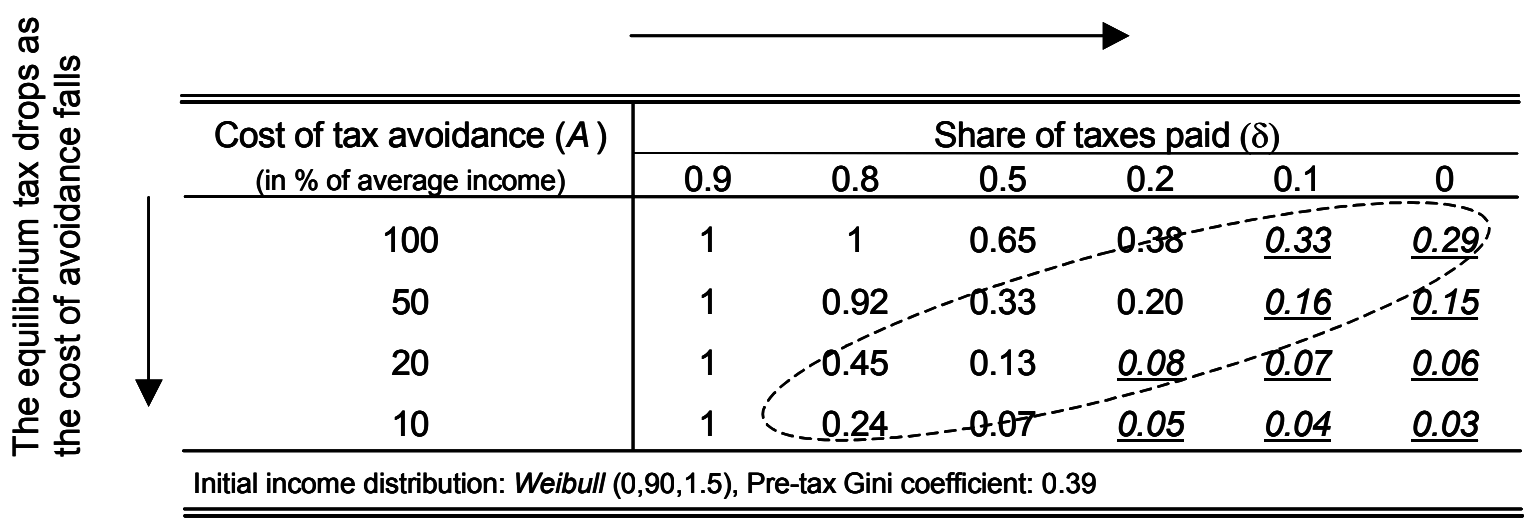

Figure 4: Equilibrium tax rates for different combinations of costs and shares avoided. The underlined figures are equilibria where a coalition of rich and poor would prefer an increase of the tax and the median income earner is not decisive.

The intermediate and more realistic outcomes occur when the tax avoidance is characterized by, what is arguably more realistic tax avoidance parameters.

In the lower left-hand part of the table, we have combinations of low cost and low effectiveness also yield intermediate tax rates. ${ }^{17}$ These parameter combinations

\footnotetext{
${ }^{17}$ It is worth emphasizing the context in which the expresion "low effectiveness" is used. In many cases, tax reductions of twenty percent are not small, nor easily achieved, but in this setting, they are "small" when contrasted to "advanced", complete tax avoidance.
} 
correspond to activities such as buying standard legal advice in some form. To exemplify, if individuals by spending the equivalent of 10 to 20 percent of the average income can reduce their tax burden by 20 percent, the resulting equilibrium tax rates would be between 25 and 45 percent. In these situations the equilibrium number of individuals who would choose to invest in tax avoidance is around 10 percent of the population. Politically, these cases are characterized by the lower half of the income distribution being in favor of a higher tax rate and, consequently, more redistribution, while the richer half would prefer a lower tax rate. This means that the median income earner is the decisive voter in all these cases.

Finally, in the top right-hand corner avoidance is very costly but also very effective. It takes a large investment, but once that has been made, the actual tax rate faced by a wealthy individual can be brought close to zero. This characterization is not unlike a description of existing advanced tax planning schemes using tax haves, or other tax shelters. An interesting aspect of these equilibria is that the fraction of the population that in equilibrium invests in tax avoidance is relatively small (around 0.5 percent). This indicates that it is not necessarily the number of individuals engaged in avoidance which measures its importance. What holds taxes down in these situations is the tax avoidance possibility. That is, the threat that an increase in the tax rate would lead to such an increase of tax avoidance making the decisive voter prefer to hold the tax rate down. Politically, these cases are interesting since the median voter is not decisive in any of the underlined equilibria. When avoidance is complete, the proponents for a marginally higher tax rate are, in equilibrium, composed of both ends of the distribution.

Even though it is a theoretical possibility, no cases of multiple equilibria, nor cases of nonexistence of equilibria were found in the simulations. The qualitative results are not affected by changing the underlying distribution. The size of the equilibrium tax rate does, however, change slightly depending on the pre-tax income distribution. $^{18}$

\footnotetext{
${ }^{18}$ The model has been solved for a number of pre-tax income distributions with Gini coefficients in the range 0.30 to 0.49 and the qualitative results remain the same.
} 


\subsection{Equilibria with both standard and advanced avoidance opportunities}

In reality, it seems likely that both advanced, as well as less advanced, tax avoidance schemes are simultaneously available to people. This fact can easily be incorporated into the model. We now study situations where individuals can choose whether to invest in cheap, but less effective, tax avoidance, expensive and efficient avoidance, or not invest in tax avoidance at all. To be specific, the induced utility function, previously given by equation (2), is now

$$
v(w, t)=\max \left\{\begin{array}{cc}
u(w-t w+r) & \text { if } w \leq w^{* 1} \\
u(w-A 1-\delta 1 t w+r) & \text { if } w^{* 1}<w \leq w^{* 2} \\
u(w-A 2-\delta 2 t w+r) & \text { if } w>w^{* 2}
\end{array}\right.
$$

where parameters $(A 1, \delta 1)$ characterize simple tax avoidance, while $(A 2, \delta 2)$ are the parameter values for the advanced avoidance scheme. At any tax rate, individuals with an income below $w^{* 1}=A 1 /(1-\delta 1) t$ do not avoid taxes at all, those with an income above $w^{* 1}$, but below $w^{* 2}=A 2 /(1-\delta 2) t$, choose the simple avoidance scheme, while those with an income above $w^{* 2}$ invest in the advanced avoidance scheme. ${ }^{19}$ The impact on the size of transfers, previously given by equation (5), is now

$$
r(t)=t \int_{0}^{w^{* 1}(t)} w \varphi(w) d w+\delta 1 t \int_{w^{* 1}(t)}^{w^{* 2}(t)} w \varphi(w) d w+\delta 2 t \int_{w^{* 2}(t)}^{\infty} w \varphi(w) d w .
$$

Even though solving for the political equilibrium involves a few additional steps, the method is precisely the same as in the cases with only one form of avoidance available at a time.

Table 1 shows the political equilibrium tax rates, $t^{*}$, for cases where the simple tax avoidance scheme is fixed (at different values for each column) while the cost of completely avoiding taxes is varied (vertically). As in the previous section the cost of tax avoidance is given as a percentage of average income and the underlying pre-

\footnotetext{
${ }^{19}$ In situations where $w^{* 2}<w^{* 1}$, clearly no one uses the simple tax avoidance scheme. Such a case is analogous in outcome to situations where only the advanced scheme is available.
} 
tax income distribution is $\operatorname{Weibull}(0,90,1.5)$ with a Gini-coefficient of approximately 0.39. The cost of small scale tax planning is set to be between 6 and 25 percent of the average income, while the tax reductions to which this leads, vary from 10 to 30 percent. The cost of complete avoidance varies between 60 percent of the average income and 2.5 times the average income.

\begin{tabular}{c|ccc|ccc|cccc}
\hline \hline \multirow{2}{*}{$\begin{array}{c}\text { Cost (A2) for } \\
\delta 2=0\end{array}$} & \multicolumn{3}{|c|}{ Cost of regular avoidance $(A)$ for different tax shares $(\delta)$} \\
& \multicolumn{3}{|c}{$\delta=0.9$} & \multicolumn{3}{c}{$\delta=0.8$} & \multicolumn{3}{c}{$\delta=0.7$} \\
250 & 6 & 12 & 25 & 6 & 12 & 25 & 6 & 12 & 25 \\
\cline { 2 - 9 } 190 & 0.54 & 0.63 & 0.72 & 0.14 & 0.27 & 0.53 & 0.08 & 0.16 & 0.31 \\
150 & 0.42 & 0.50 & 0.54 & 0.14 & 0.27 & 0.47 & 0.08 & 0.16 & 0.31 \\
120 & 0.36 & 0.42 & 0.43 & 0.14 & 0.27 & 0.41 & 0.08 & 0.16 & 0.30 \\
100 & 0.31 & 0.36 & 0.36 & 0.14 & 0.27 & 0.36 & 0.08 & 0.16 & 0.30 \\
60 & 0.27 & 0.29 & 0.29 & 0.14 & 0.27 & 0.29 & 0.08 & 0.16 & 0.27 \\
& 0.18 & 0.18 & 0.18 & 0.14 & 0.18 & 0.18 & 0.08 & 0.15 & 0.18 \\
\hline
\end{tabular}

Table 1: Equilibrium tax rates with both regular and advanced avoidance

The simultaneous availability of both small-scale and advanced tax avoidance has a downward, enveloping effect on the equilibrium tax rate. The downward pressure on the tax rate is easily understood. Whereas an increase of the tax rate previously lead to a marginal loss of tax base at one level in the income distribution, the decisive voter must now take into account both the marginal loss at the very top of the distribution (additional complete avoidance) as well as the increase in "standard" avoidance. The enveloping effect comes from that either one of these effects can be more or less severe for the decisive voter. For example, if the biggest marginal loss of tax base, from an increase of the tax rate, comes from more individuals investing in standard tax avoidance, preventing this (by keeping the tax rate low) becomes most important. Regardless of increases in the cost of complete avoidance, the tax 
rate remains low. An example of this is the case when, $A=6$ and $\delta=0.8$, and the equilibrium tax remains 0.14 regardless of the cost $(A 2)$ of complete avoidance changing. The opposite can, of course also happen. When $A 2=60$ it does not matter what the cost of standard avoidance $(\delta=0.9)$ is, the equilibrium remains 0.18 .

Regarding the number of individuals investing in tax avoidance, typical equilibrium shares lie between 5 and 15 percent for standard tax avoidance, and between 0.1 and 0.5 percent for complete avoidance. The share of total income lost due to tax avoidance ranges from 0.5 to 6 percent for the equilibria shown in Table 1.

\section{Confronting the model with data}

Confronting the model with data is difficult for two reasons. First, the level of abstraction is such that it is not possible to find exact real-world counterparts to the variables. There is, for example, no obvious analogue to the tax rate determined by majority vote in the model. Second, there are no direct estimates of the tax avoidance parameters. Still, there are ways of comparing the model predictions with real-world observations.

Figure 5 illustrates the basic structure of the model outlined and solved in the previous sections. Given a pre-tax distribution of income and assuming commonknowledge of the cost and effectiveness of the tax avoidance opportunities there is, as was shown in the previous section, a unique equilibrium tax rate, with corresponding levels of avoidance activities and redistribution.

Out of the data needed to test the model, there are relatively good estimates of (pre-tax) market income (as defined in the Luxembourg Income Study, henceforth LIS), but only some country-specific, indirect data on the effectiveness of tax avoidance and no data on the cost of avoidance. However, using the data which is available and the fact that there is a unique $t^{*}$ for every cost of avoidance (given the efficiency $\delta$ ), still leaves several dimensions against which the model predictions can be compared. 


\begin{tabular}{|c|c|c|}
\hline$\underline{\text { Model-input }}$ & $\underline{\text { Model-output }}$ & $\underline{\text { Additional results }}$ \\
\hline $\begin{array}{l}\text { - Tax avoidance } \\
\text { parameters, }(\mathrm{A}, \delta)\end{array}$ & $\begin{array}{l}\text { Equilibrium } \\
\text { tax rate, } t^{*}\end{array}$ & $\begin{array}{l}\text { The number of people } \\
\left.\text { that avoid taxes (at } t^{*}\right)\end{array}$ \\
\hline $\begin{array}{l}\text { Approximate estimates of } \delta \\
\text { can be extracted form country } \\
\text { studies of tax avoidance. }\end{array}$ & $\begin{array}{l}\text { Can be approximated } \\
\text { by total tax revenue } \\
\text { as a share of GDP. }\end{array}$ & $\begin{array}{l}\text { Approximate estimates can be } \\
\text { found for single countries. }\end{array}$ \\
\hline $\begin{array}{l}\text { Pre-tax income- } \\
\text { distribution, } \Phi(\mathrm{w})\end{array}$ & $\begin{array}{l}\text { - Distribution of } \\
\text { disposable income }\end{array}$ & $\begin{array}{l}\text { - The amount of tax revenue } \\
\text { lost due to avoidance }\end{array}$ \\
\hline $\begin{array}{l}\text { Can be approximated by the } \\
\text { distribution of market income. }\end{array}$ & $\begin{array}{l}\text { Can be proxied by measures } \\
\text { of disposable income. }\end{array}$ & $\begin{array}{l}\text { Approximate estimates can be } \\
\text { found for single countries. }\end{array}$ \\
\hline
\end{tabular}

Figure 5: The input- and output components of the model and their respective proxies.

To exemplify, consider the case of Sweden in 1980 for which there is data on market income as well as a study of tax avoidance activities in that year. The distribution of market-income in Sweden 1980 had, according to the LIS estimate, a pre-tax Gini coefficient of 0.41. Setting the dispersion parameter $(c)$ in the Weibull distribution $(0,90, c)$ to $c=0.4$, gives a pre-tax Gini coefficient of 0.41 in the model. Furthermore, according to a study of tax avoidance by Malmer and Persson (1994), individuals in the top decile managed to avoid about $20 \%$ of their official tax burden in 1980, while the rest of the population avoided virtually nothing. This suggests setting $\delta=0.8$, which means precisely that an investment in tax avoidance reduces the tax payment by $20 \%$. There is no information on the cost of tax avoidance $(A)$. However, since there is a monotone relationship between $A$ and the equilibrium tax rate $t^{*}$ for a given $\delta$, we can use a proxy of $t^{*}$ to close the model. Using the total tax revenue as a share of GDP, which was $49 \%$ in 1980, as a proxy of the tax rate $t^{*}$ implies that if the model is to match this, the cost of tax avoidance must be set to $A=22$ (expressed in percent of average income). This does not seem to be an unreasonable cost for avoiding $20 \%$ of taxes.

Even though data on the equilibrium tax rate must be used to close the model, there remains three results which can be compared to other data (whenever avail- 
able): the distribution of disposable income, the amount of taxes avoided, and the number of individuals who, in equilibrium, invest in tax avoidance. For the case of Sweden 1980, the LIS has data on the distribution of disposable income and the study by Malmer and Persson (1994) contains information suggesting that the richest $10 \%$ of the population avoided taxes.

Table 2 shows the model's predicted measures of disposable income and the number of individuals who invest in tax avoidance. The predictions for income inequality come surprisingly close to the observed measures. Out of the 21-point drop in the Gini coefficient, 19 points can be explained by the model's proportional tax scheme. Furthermore, the model's equilibrium prediction regarding the share of the population who avoid taxes is $9 \%$, which corresponds well to the observed avoidance in the top decile.

\begin{tabular}{|c|c|c|c|c|c|c|c|}
\hline \multicolumn{8}{|c|}{ Model } \\
\hline \multicolumn{2}{|c|}{ Parameters } & \multirow[b]{2}{*}{$t^{*}$} & \multirow[b]{2}{*}{$\begin{array}{l}\text { Pop. share } \\
\text { of avoiders }\end{array}$} & \multicolumn{4}{|c|}{ Inequality measures } \\
\hline $\begin{array}{c}\text { Avoidance } \\
\text { parameters }\end{array}$ & $\begin{array}{l}\text { Pre-tax } \\
\text { Gini } \\
\end{array}$ & & & $P_{90} / P_{10}$ & $P_{90} / P_{50}$ & $P_{80} / P_{20}$ & Gini \\
\hline $\begin{array}{c}\text { Model } \\
\delta=0.8, \mathrm{~A}=22 \\
\end{array}$ & 0.41 & 0.49 & $9 \%$ & 2.56 & 1.67 & 1.88 & 0.224 \\
\hline \multicolumn{8}{|c|}{ Data } \\
\hline & & & & \multicolumn{4}{|c|}{ Inequality measures } \\
\hline $\begin{array}{l}\text { Avoidance } \\
\text { parameters }\end{array}$ & $\begin{array}{c}\text { Pre-tax } \\
\text { Gini }\end{array}$ & $\begin{array}{l}\text { Tax rev. as } \\
\% \text { of GDP }\end{array}$ & $\begin{array}{l}\text { Estim. share } \\
\text { of avoiders }\end{array}$ & $P_{90} / P_{10}$ & $P_{90} / P_{50}$ & $P_{80} / P_{20}$ & Gini \\
\hline $\begin{array}{c}\text { Estimates } \\
\delta=0.8, \mathrm{~A} \text { (n.a) } \\
\end{array}$ & 0.41 & 49 & $10 \%$ & 2.43 & 1.51 & 1.76 & 0.197 \\
\hline
\end{tabular}

Table 2: Testing the model on data for Sweden 1980

Another case for which there is data is Denmark in 1995. As in the above case, we start by approximating the distribution of initial income. Setting $c=1.41$ gives a pre-tax income distibution with the same Gini-coefficient as that reported by LIS for Denmark 1995. There are no observations on the tax avoidance parameters, but assuming that $\delta=0.8$ (as in the case of Sweden) we can again close the model by setting $A$ so as to get an equilibrium tax rate in the model, that matches the observed tax revenue as a share of GDP (which is $49 \%$ ). Solving the model with a 
pre-tax distribution with Gini equal to 0.42 and tax avoidance parameters $\delta=0.8$ and $A=20$, gives an equilibrium tax rate of $49 \%$ (this we know since we used this in the calibration), and predictions on the distribution of after-tax disposable income, on the number of individuals who avoid taxes, and on the amount of money being avoided. As before, the predictions on disposable income can be compared to estimates in the LIS, while a study by Nielsen et al. (2001) estimate that $4.1 \%$ of the Danish income-tax base that year were lost due to international income shifting. This figure can be compared to the predicted amount of money which is not taxed in the model due to tax avoidance. Table 3 reports these comparisons. ${ }^{20}$ Again, the measures of disposable income are relatively close to the observations and the share of total income lost due to avoidance turns out to be $4.6 \%$, which is also close to the estimated $4.1 \%$ in Nielsen et al. (2001). ${ }^{21}$

\begin{tabular}{|c|c|c|c|c|c|c|c|}
\hline \multicolumn{8}{|c|}{ Model } \\
\hline \multicolumn{2}{|c|}{ Parameters } & \multirow[b]{2}{*}{$t^{*}$} & \multirow[b]{2}{*}{$\begin{array}{c}\text { Income-share } \\
\text { avoided }\end{array}$} & \multicolumn{4}{|c|}{ Inequality measures } \\
\hline $\begin{array}{l}\text { Avoidance } \\
\text { parameters }\end{array}$ & $\begin{array}{l}\text { Pre-tax } \\
\text { Gini }\end{array}$ & & & $P_{90} / P_{10}$ & $P_{90} / P_{50}$ & $P_{80} / P_{20}$ & Gini \\
\hline $\begin{array}{c}\text { Model } \\
\delta=0.8, \mathrm{~A}=20 \\
\end{array}$ & 0.42 & 0.49 & $4.6 \%$ & 2.79 & 1.72 & 2.01 & 0.242 \\
\hline \multicolumn{8}{|c|}{ Data } \\
\hline & & & & \multicolumn{4}{|c|}{ Inequality measures } \\
\hline $\begin{array}{c}\text { Avoidance } \\
\text { parameters }\end{array}$ & $\begin{array}{c}\text { Pre-tax } \\
\text { Gini }\end{array}$ & $\begin{array}{l}\text { Tax rev as } \\
\% \text { of GDP } \\
\end{array}$ & $\begin{array}{l}\text { Estim share of } \\
\text { inc. anoided }\end{array}$ & $P_{90} / P_{10}$ & $P_{90} / P_{50}$ & $P_{80} / P_{20}$ & Gini \\
\hline $\begin{array}{c}\text { Estimates } \\
\delta=?, \mathrm{~A}=?\end{array}$ & 0.42 & 49 & $4.1 \%$ & 3.18 & 1.63 & 2.19 & 0.263 \\
\hline
\end{tabular}

Table 3: Testing the model on data for Denmark 1995

Besides data on market income, disposable income and tax rates, the above examples rely on additional information about tax avoidance. Even though such data is scarce, the studies that do exist can give indications about the range of plausible avoidance parameters for other countries. Very broadly, they studies seem to suggest the following: individuals in the top income decile can avoid taxes in an

\footnotetext{
${ }^{20}$ The small differences compared to the Swedish example above are due to the different pre-tax income distribution.

${ }^{21}$ The estimated share of total income missing is $6 \%$ in 1996 and $4.6 \%$ in 1997.
} 
order of magnitude of about $10-20 \%{ }^{22}$ Those in the top income percentile seem to have even larger possibilities to avoid taxes and some can probably even completely avoid taxes. ${ }^{23}$ As mentioned above, measures of aggregate avoidance activity suggest that approximately $2-6 \%$ of the income tax base is diverted from taxation.

Table 4 shows the political equilibrium tax rate $\left(t^{*}\right)$, the share of total income avoided and the resulting measures of disposable income inequality for a range of plausible parameterizations. (The choice of initial income distribution is set so as to approximate the average pre-tax Gini coefficient for all available observations reported in LIS. ${ }^{24}$ The average values of the model predictions can be compared to the average values of their corresponding measures taken from recent studies of income inequality). ${ }^{25}$

The results are very surprising. When solving the model for a reasonable range of tax avoidance parameters, given an initial income distribution with the same Gini coefficient as that of average actual market income, the resulting measures of income inequality are, on average, very close to their corresponding average measures in the data. It is also worth emphasizing that these results are political equilibria, that is, the results of majority preferred tax and transfer schemes, given the possibilities to avoid taxes.

A natural question is, of course, if this is just a lucky coincidence for the average values of income inequality. A check of this can be made by dividing the data into

\footnotetext{
${ }^{22}$ Based on Malmer and Persson (1994) and Lang et al. (1997), taking into account that these studies are based on data from high tax situations. Avoidance can be expected to be higher in these cases than on average.

${ }^{23}$ Malmer and Persson (1994) estimate that one tenth of the individuals in the top decile reduced their taxes by half.

${ }^{24}$ Data for market income Gini is taken from OECD Economic Review No. 29, 1997 and $O E C D$ Social Policy Studies No. 18, 1995 (based on LIS) and consists of 34 observations, with an average market income Gini of 0.39 .

${ }^{25}$ Data is taken from the Luxembourg Income Study (LIS), Gottschalk and Smeeding (1997), (which is also based on LIS), and from figures reported in OECD Economic Review No. 29, 1997/II. All averages used are simple, (non-weighted), averages of all observations reported in the sources (LIS data is taken from the latest Key Figures and from OECD Social Policy Studies No. 18, 1995. When "all countries, all years" are included, this means 26 OECD countries for the years ranging from 1969 to 1997, with a total of 97 (country/year) observations. When only the "most recent years" are included, this means 25 OECD countries between 1994 and 1997. (Note that when calculating the average, the most recent years are not included since they are already in the figures for all observations).
} 


\begin{tabular}{|c|c|c|c|c|c|c|}
\hline \multicolumn{7}{|c|}{ Model Predictions } \\
\hline Parameters $(A, \delta)$ & & & \multicolumn{4}{|c|}{ Income Inequality Measures } \\
\hline $\begin{array}{l}\text { Fix A1=6, } \delta 1=0.9 \\
\text { vary A2 for } \delta 2=0\end{array}$ & $t^{*}$ & $\begin{array}{l}\text { Income share } \\
\text { avoided }\end{array}$ & $P_{90} / P_{10}$ & $P_{90} / P_{50}$ & $P_{80} / P_{20}$ & Gini \\
\hline 200 & 0.45 & 0.040 & 2.80 & 1.69 & 1.97 & 0.246 \\
\hline 150 & 0.36 & 0.023 & 3.27 & 1.80 & 2.20 & 0.275 \\
\hline 100 & 0.27 & 0.012 & 3.94 & 1.91 & 2.50 & 0.304 \\
\hline Average & 0.36 & 0.025 & 3.34 & 1.80 & 2.22 & 0.275 \\
\hline $\begin{array}{l}\text { Fix } \mathrm{A} 1=12, \delta 1=0.8 \\
\text { vary A2 for } \delta 2=0\end{array}$ & $t^{*}$ & $\begin{array}{l}\text { Income share } \\
\text { avoided }\end{array}$ & $P_{90} / P_{10}$ & $P_{90} / P_{50}$ & $P_{80} / P_{20}$ & Gini \\
\hline 200 & 0.27 & 0.014 & 4.01 & 1.92 & 2.50 & 0.305 \\
\hline 150 & 0.27 & 0.015 & 4.01 & 1.92 & 2.50 & 0.305 \\
\hline 100 & 0.24 & 0.009 & 4.27 & 1.95 & 2.67 & 0.314 \\
\hline Average & 0.26 & 0.013 & 4.10 & 1.93 & 2.56 & 0.308 \\
\hline Average (model) & 0.31 & 0.019 & 3.72 & 1.87 & 2.39 & 0.292 \\
\hline \multicolumn{7}{|c|}{ Data } \\
\hline \multirow[t]{2}{*}{ Source of data } & \multicolumn{6}{|c|}{ Income Inequality Measures } \\
\hline & $t^{*}$ & $\begin{array}{c}\text { Income share } \\
\text { avoided }\end{array}$ & $P_{90} / P_{10}$ & $P_{90} / P_{50}$ & $P_{80} / P_{20}$ & Gini \\
\hline LIS (all years) & 0.32 & - & 4.00 & 1.89 & 2.41 & 0.288 \\
\hline LIS (recent years) & 0.36 & - & 4.19 & 1.93 & 2.46 & 0.298 \\
\hline G \& S (JEL, 97) & 0.38 & - & 3.52 & n.a. & n.a. & 0.274 \\
\hline Average (data) & $0.32^{a}$ & $0.02-0.06^{b}$ & 3.76 & 1.89 & 2.41 & 0.286 \\
\hline \multicolumn{7}{|c|}{$\begin{array}{l}\text { Calculations are based on a pre-tax income distribution: Weibull }(0,90,1.5) \text {, with a Gini coefficient }=0.39 \\
\text { Actual average market income Gini coefficient }=0.39 \text { (average of the values reported in the data sources) } \\
a \text { : Measured as total tax revenue as percentage of GDP, unweighted average for all countries in LIS for the } \\
\text { years 1965-1995, which is the same time span as for the LIS inequality measures, (Source: OECD). } \\
\text { b: Based on estimates by Gordon and Nielsen (1997), Nielsen et al. (2001) (for Denmark), Löfvist (2001) } \\
\text { (for Sweden), Lang et al. (1997) for Germany, and by the IRS (for USA), (see Andreoni et al. (1998)). }\end{array}$} \\
\hline
\end{tabular}

Table 4: Comparison of average model-outcomes for different tax-avoidance parameters and pre-tax Gini of 0.39, and average values of observed data 
two groups, one with the most unequal observations of market income distribution, and one with the most equal observations. ${ }^{26}$

\begin{tabular}{c|ccccc}
\hline \hline Unequal market income & \multicolumn{5}{c}{ Income Inequality Measures } \\
\hline $\begin{array}{c}\text { Model pre-tax income Gini }=0.346 \\
\text { Average market income Gini }=0349\end{array}$ & $t$ & $P_{90} / P_{10}$ & $P_{90} / P_{50}$ & $P_{80} / P_{20}$ & Gini \\
\hline Average (model) & 0.30 & 4.84 & 2.18 & 2.90 & 0.327 \\
Average (data) & 0.39 & 3.77 & 1.84 & 2.35 & 0.284 \\
Average (US \& UK only) & 0.30 & 5.11 & 2.04 & 2.89 & 0.331 \\
\hline \hline Equal market income & \multicolumn{5}{c}{ Income Inequality Measures } \\
\hline \hline Model pre-tax income Gini $=0.346$ & $t$ & $P_{90} / P_{10}$ & $P_{90} / P_{50}$ & $P_{80} / P_{20}$ & Gini \\
Average market income Gini $=0349$ & 0.37 & 3.30 & 1.70 & 2.20 & 0.263 \\
Average (model) & 0.28 & 3.30 & 1.74 & 2.17 & 0.256 \\
Average (data)
\end{tabular}

Table 5: The same comparison as in Table 7 but with the sample divided into "equal" and "unequal" countries

The average market income Gini coefficient for the unequal observations is 0.443 , and for the most equal observations, 0.349. In Table 5, the average values of inequality measures for these groups are compared to the model predictions. The equilibria are computed for the same tax avoidance parameters as those used in Table 4, and assuming initial distributions of pre-tax income that approximate the groups of unequal and equal market income, respectively. ${ }^{27}$

Again, the outcome of the model is relatively close to observed data, with the exception of the unequal economies when all countries are included. The reason is that some countries, such as Sweden and Denmark, have high market income Gini coefficients (around 0.44), but very low levels of disposable income Gini coefficients (around 0.23), which pull down the average considerably. When, for example, only

\footnotetext{
${ }^{26}$ There are 34 observations of market income, and the bases for the split of countries is a simple division into the 17 most equal, and the 17 least equal, observations.

${ }^{27}$ An initial income distribution which is Weibull $(0,90,1.2)$ has a Gini coefficient of 0.449 . This is chosen as an approximation of the average for "unequal" countries. Changing the distribution to Weibull $(0,90,1.8)$ gives a distribution with a Gini coefficient of 0.346 , which is taken to approximate the average of "equal" countries.
} 
considering data for the U.S. and the U.K., the predictions of the model are much closer.

Overall, the model seems to be consistent with the data, for the range of tax avoidance parameters considered above. Measures of disposable income inequality, as well as estimates on how much money is being avoided, can be closely matched for single countries where partial data on tax avoidance is available. Taking the average for a range of plausible avoidance parameters also gives predictions matching the corresponding measures for a whole group of countries, both on average, and for countries with equal and unequal pre-tax income distributions considered separately. Clearly, these results should be interpreted with caution given the crudeness of the measures used.

\section{Summary and concluding remarks}

This paper set out to study the redistributive as well as the political effects of introducing tax avoidance in a setting where the tax rate is determined in a majority election. In the introduction, three questions were raised which can now be answered.

The first question concerned the possibilities to tax individuals and redistribute income. Taken literally, the model developed in this paper suggests that the very richest part of the population will always, in equilibrium, invest in tax avoidance. As a consequence, everyone above a critical income level, will pay a smaller share of their income in taxes compared to the rest of the population, even if the official tax rate is proportional. In situations where it is possible to completely avoid taxes, the very richest part of the population is not affected by increased taxation. It is interesting to note that these features could, in an explicitly dynamic context, enable high levels of redistributive taxes "without impeding the investments by the rich" (Saint-Paul and Verdier, (1996), p. 726). This could, in turn, change the analysis of how inequality affects growth (see e.g. Alesina and Rodrik (1994) and Persson and Tabellini (1994a). The model also shows how the tax avoidance possibilities create a trade-off between taxation and the tax base. Increasing the tax rate leads, on the 
one hand, to larger tax payments from those who pay the tax but, on the other hand, it also induces a larger share of the population to invest in tax avoidance and, hence, decreases the tax base. For reasonable parameters, the tax avoidance opportunities limit the demand for complete equalization of income, and the equilibrium tax rate chosen by a majority is smaller than one.

Closely linked to these observations is the second question in the introduction, concerning the effects on the distribution of disposable income. For reasonable parameterizations of the model, $5-20 \%$ of the population avoid $10-20 \%$ of their official tax payments and a very small fraction - less than $0.5 \%$ - completely avoids taxes. These observations are consistent with studies on tax avoidance activities.

The third question posed in the introduction dealt with the potential political effects of the introduction of tax avoidance. These are perhaps the most interesting. Even though it is obvious that individuals with a higher than average income never benefit from positive taxes in a purely redistributive setting, they may prefer a higher tax rate than that preferred by the median income earner. This, in turn, means that the median income earner is not necessarily the decisive voter. Instead, in equilibrium, a coalition of the poor and the very rich may favor an increase of the tax rate. In a situation where complete tax avoidance possibilities are available, this type of coalition is always the equilibrium outcome, and the tax rate is higher than that preferred by the median income earner. Such a situation can be described as an inverse of Director's law, with redistribution going from the middle towards the ends of the income distribution. Allowing for a broader interpretation of tax avoidance, the investments made by the rich could also be seen as political contributions in exchange for "tailored tax cuts", creating an endogenous wealth-biased political mechanism (see e.g. Bénabou (2000)).

Quantitatively, the predictions of the model depend on the tax avoidance parameters and the choice of the initial income distribution. When choosing a reasonable range of parameter values, based on observable tax rates and estimates of total income tax avoidance, the equilibrium tax rate is, on average, around 30 percent, 
between one and six percent of total income disappear from the redistributive system due to tax avoidance, and the Gini coefficient drops by 10 to 15 points as a consequence of taxes and transfers. Between 5 and 20 percent of the population engage in small scale tax avoidance, which means that they reduce their official tax payment by 10 to 20 percent, while a very small share of the population makes costly investments in tax avoidance to completely avoid taxation.

When comparing the model predictions for income inequality to actual observations, they turn out to be surprisingly close, both on average and for groups of countries, as well as for single countries. Even though such comparisons should be interpreted with care, they seem to suggest that, despite the simplicity of the model, it does seem to capture important aspects of reality. 


\section{References}

[1] Agell, J., P. Englund and J. Södersten. (1996). Tax reform of the century - the Swedish experiment. National Tax Journal 49: 643-664.

[2] Agell, J., and M. Persson. (2000). Tax arbitrage and labor supply. Journal of Public Economics 78: 3-24.

[3] Alesina, A., and D. Rodrik. (1994). Distributive politics and economic growth. Quarterly Journal of Economics 109: 465-490.

[4] Andreoni, J., Erard, B., and J. Feinstein. (1998). Tax compliance. Journal of Economic Literature 36: 818-860.

[5] Auerbach, A.J., and J. Slemrod. (1997). The economic effects of the Tax Reform Act of 1986. Journal of Economic Literature 35: 589-632.

[6] Austen-Smith, D. and J. Banks. (1999). Positive Political Theory I. Ann Arbor: Michigan University Press.

[7] Bénabou, R. (2000). Unequal societies: Income distribution and the social contract. American Economic Review 90(1): 96-129.

[8] Black, D. (1948). The decisions of a committee using spacial majority. Econometrica 16(3): 245-261.

[9] Epple, D., and R.E. Romano. (1996). Ends against the middle: Determining public service provision when there are private alternatives. Journal of Public Economics 62: 297-325.

[10] Fernandez, R., and R. Rogerson. (1995). On the political economy of education subsidies. The Review of Economic Studies 62: 249-262.

[11] Gordon, R., and S.B. Nielsen. (1997). Tax evasion in an open economy: Valueadded vs. income taxation. Journal of Public Economics 66: 173-197.

[12] Gottschalk, P., and T. Smeeding. (1997). Cross-national comparisons of earnings and income inequality. Journal of Economic Literature Vol. XXXV, 633687.

[13] Lang, O., Nöhrbaß, K.H., and K. Stahl. (1997). On income tax avoidance: The case of Germany. Journal of Public Economics 66: 327-347.

[14] Löfqvist, R. (1991). Tax avoidance, dividend signaling and shareholder taxation in an open economy. Department of Economics, Uppsala University, Economic Studies 55. 
[15] Malmer, H., and A. Persson. (1994). Skattereformens effekter på skattesystemets driftskostnader, skatteplanering och skattefusk (The effects of the tax reform on compliance costs, tax planning and tax fraud). In: Malmer, H., Persson A., and Å Tengblad (Eds.). Århundradets skattereform (Tax reform of the century). Stockholm, Fritzes.

[16] Mayshar, J. (1991). On taxation with costly administration. Scandinavian Journal of Economics 93(1): 75-88.

[17] Meltzer, A., and S. Richard. (1981). A rational theory of the size of government. Journal of Political Economy 89: 914-927.

[18] Myrdal, G. (1978). Dags för ett nytt skattesystem (Time for a new tax system). Ekonomisk Debatt 6: 493-506.

[19] Nielsen, S.B., Schou, P., and J.K Søbygaard. (2001). Tracing international income tax avoidance in Denmark. Paper prepared for the conference on International Mobility of the Tax Bases organized by the Economic Council of Sweden in Stockholm, November 1, 2001.

[20] OECD Economic Studies, No. 29, 1997/II.

[21] OECD Social Policy Studies, No. 18, 1995.

[22] Persson, T., and G. Tabellini. (1994a). Is inequality harmful for growth? American Economic Review 84: 600-621.

[23] Persson, T., and G. Tabellini. (1994b). Representative democracy and capital taxation. Journal of Public Economics 55: 53-70.

[24] Persson, T., and G. Tabellini. (2000). Political Economics - Explaining Economic Policy. Cambridge, MA: The MIT Press.

[25] Roberts, K.W.S. (1977). Voting over income tax schedules. Journal of Public Economics 8: 329-340.

[26] Romer, T. (1975). Individual welfare, majority voting and the properties of a linear income tax. Journal of Public Economics 4: 163-185.

[27] Saint-Paul, G. and T. Verdier. (1996). Inequality, redistribution and growth: A challange to the conventional political economy approach. European Economic Review 40: 719-728.

[28] Shackelford, D. A. (2000). The Tax Environment Facing the Wealthy, in Slemrod (ed.), Does Atlas Shrug? The Economic Consequences of Taxing the Rich. New York: Russel Sage Foundation and Cambridge, MA: Harvard University Press. 
[29] Slemrod, J. (1992). Do taxes matter? Lessons from the 1980's. American Economic Review 82(2): 250-256.

[30] Slemrod, J. and S. Yitzhaki. (2001). Tax avoidance, evasion and administration, in A. Auerbach and M. Feldstein (eds.), Handbook of Public Economics, Volume 3 , North-Holland, forthcoming.

[31] Slemrod, J. (2001). A general model of the behavioral response to taxation. International Tax and Public Finance 8(2): 119-128. 